\title{
ONE APPROACH FOR DETERMINING AVAILABILITY OF Parking Lots in Shared Parking For Disabled Person
}

\author{
Stevan Stankovski*, Srdjan Tegeltija*, Gordana Ostojic*, Igor Baranovski*, \\ Milos Stanojevic* \& Mladen Babic*
}

\author{
*University of Novi Sad, Faculty of Technical Sciences, Centar za identifikacione tehnologije \\ Trg Dositeja Obradovica 6, 21000 Novi Sad, Republic of Serbia
}
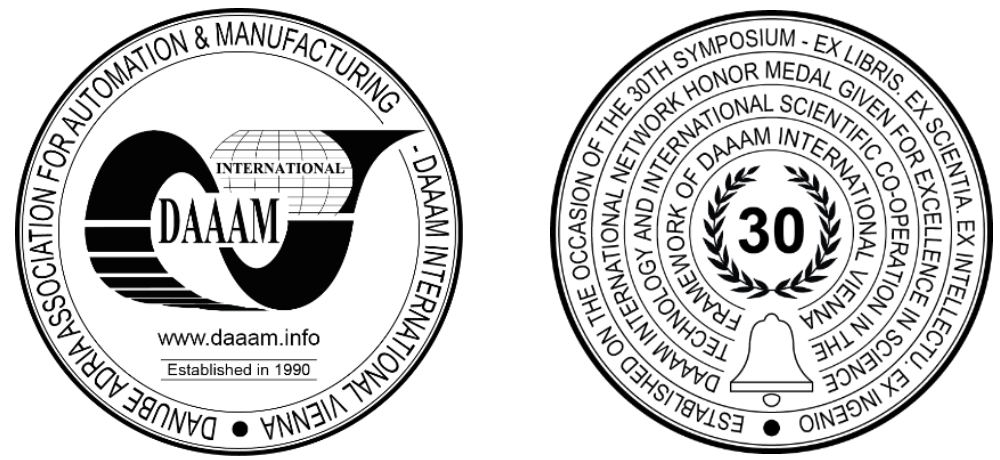

This Publication has to be referred as: Stankovski, S[tevan]; Tegeltija, S[rdjan]; Ostojic, G[ordana]; Baranovski, I[gor]; Stanojevic, M[ilos] \& Babic, M[laden] (2021). One Approach for Determining Availability of Parking Lots in Shared Parking For Disabled Person, Proceedings of the 32nd DAAAM International Symposium, pp.0316-0320, B. Katalinic (Ed.), Published by DAAAM International, ISBN 978-3-902734-33-4, ISSN 1726-9679, Vienna, Austria DOI: $10.2507 / 32$ nd.daaam.proceedings.046

\begin{abstract}
Due to the growing number of vehicles in cities, many human activities have to accommodate this fact. One of these activities is finding a free parking lot. This activity can be very stressful, especially for disabled persons, because the number of parking lots reserved for these persons is usually limited and cannot be found at every street, garage, or other parking space. There are parking lots intended and reserved for people with disabilities to make it easier for people with disabilities to perform various activities. However, in some cases, these reserved parking lots are already occupied by people with disabilities, or unscrupulous drivers occupy these parking lots. This paper presents one approach for determining the availability of parking lots in shared parking for disabled people, based on different kinds of recognition of vehicles in which owners are disabled persons or recognition of tags in which owners are disabled persons.
\end{abstract}

Keywords: parking lot; parking sensor; RFID tag; Bluetooth tag license plate recognition

\section{Introduction}

Finding free parking lots is a daily problem for drivers [1]-[3]. Finding a free parking lot can be very stressful, especially for disabled persons. The number of parking lots for these persons is usually limited and cannot be found at every street, garage, or other parking space. Limited and insufficient parking lots in cities result in the conscious or unconscious occupation of reserved parking lots reserved for people with disabilities by other drivers. In research published in papers [4]-[6], some potential solutions to the problem of detecting the occupancy of parking spaces reserved for people with disabilities have been proposed. However, monitoring and detecting illegal occupancy of parking spaces reserved for people with disabilities is only a tiny part of the problems these people face. The issues faced by people with disabilities are much broader. 
They consist of the registration of vehicles owned by people with disabilities, the registration of people with disabilities to obtain dedicated permits for the use of parking spaces reserved for people with disabilities, the search for free parking spaces reserved for persons with disabilities, removal of illegally parked vehicles from places reserved for persons with disabilities, etc.

This paper presents one approach for determining the availability of parking spaces for people with disabilities by defining a model that will connect people with disabilities, organizations for people with disabilities located in different cities, all public companies that provide parking services, all organizations that define parking policies in cities and systems for collecting data on the state of occupancy of parking spaces reserved for people with disabilities based on Internet of Things (IoT) technologies into one whole. The Internet of Things (IoT) describes the network of physical objects (things) that are embedded with sensors, software, and other technologies to connect and exchange data with other devices and systems over the Internet [7]-[11]. The proposed model would enable faster and easier obtaining of dedicated parking permits for persons with disabilities and a quick insight into the current state of parking spaces intended for persons with disabilities. Furthermore, integrating the Lean concept will further improve the proposed model [12], [13].

\section{Model for SDPS (Shared Disabled Parking System)}

The current situation in the city of Novi Sad was taken as the basis for the development of the SDPS model for parking space sharing. In Novi Sad, people with disabilities are organized in a local organization. This local organization has its database of people with disabilities, and for those who have vehicles, appropriate parking permits are issued in the form of stickers. Each sticker is designated for a valid vehicle license plate and is affixed to the vehicle's windscreen. The validity period of the sticker is determined by the validity period of the license plate. At the same time, there is information on the vehicle's license plate in the database. From the public company "Parking Service"(provider of parking services in Novi Sad), data on the number and location of parking spaces for people with disabilities are obtained. This company also takes care of the maintenance and marking of these parking spaces. City policies define the manner of using the parking spaces for people with disabilities. These policies determine in what time interval parking spaces for the people with disabilities can be used. The situation is similar in other cities in Serbia. The idea of SDPS is that all organizations for people with disabilities located in different cities, all public companies that provide parking services, and all organizations that define parking policies in cities are connected into one whole. A schematic representation of the model for SDPS is shown in figure 1 .

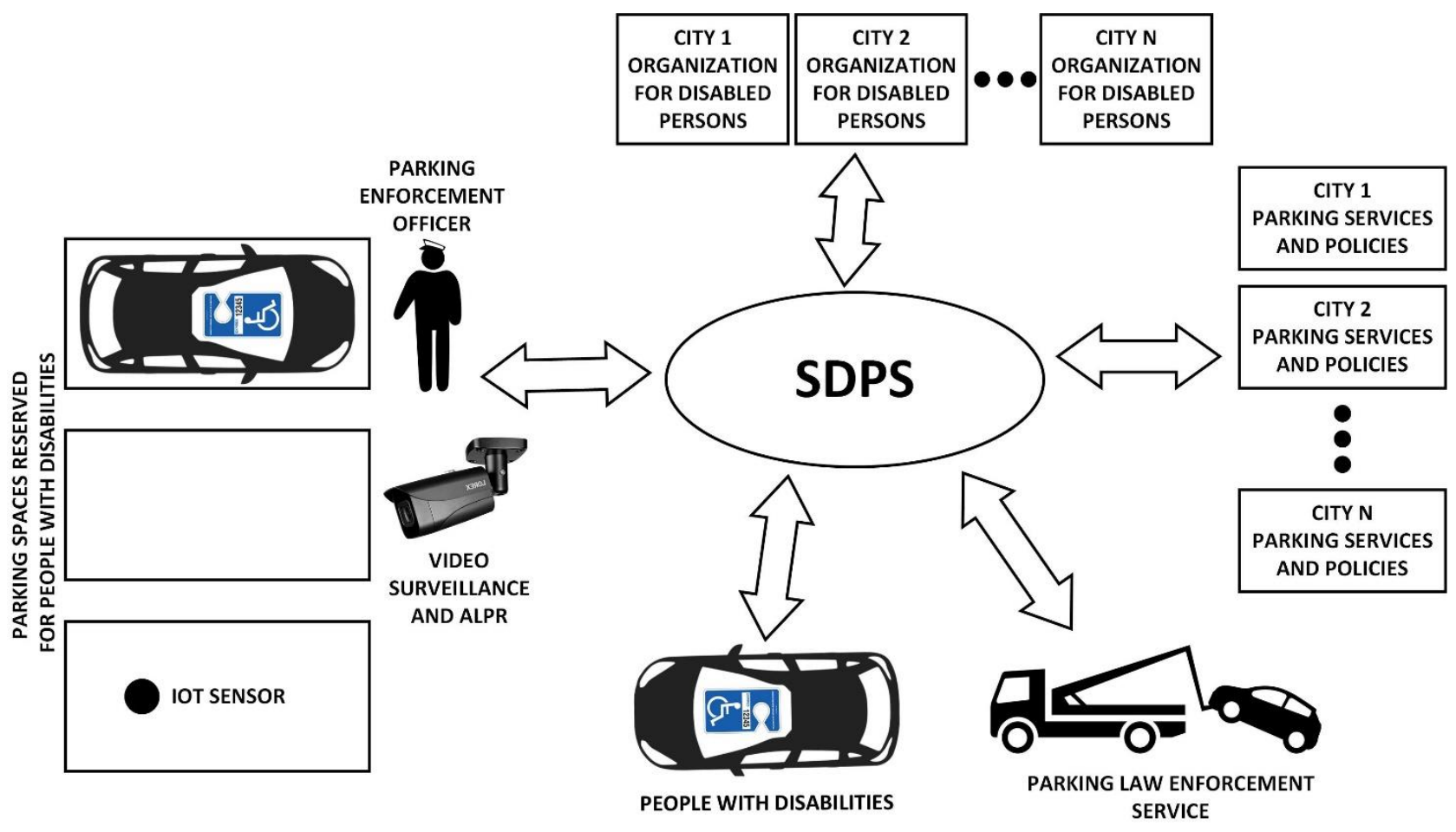

Fig. 1. Schematic representation of the model for SDPS

There are several advantages that the proposed model for SDPS provides. Granting special parking permits to people with disabilities would be simplified and accelerated. City policies and additional services that companies offer to users with disabilities would be harmonized in all cities. Such a centralized system would also make it possible to control the occupancy of parking spaces for people with disabilities. People with disabilities would have an insight into the condition of the parking space in real-time, and, based on that, they could plan to perform various activities more efficiently. 
Depending on the possibility of implementation, parking occupancy data can be obtained in three ways:

1- By reading the number of the disability sticker/vehicle license plate number by the parking enforcement officer

2- By reading the car registration number using a video surveillance camera

3- By reading RFID/Bluetooth tags and IoT sensors.

In the event of illegal occupation of a parking space, the parking law enforcement officers would be automatically notified. Then, with an additional check, the parking law enforcement officers would apply a defined penalty policy, after which unscrupulous drivers would be fined, and their vehicle would be removed.

\section{Experimental setup}

An experimental environment was formed to test the proposed SDPS model. The experimental environment consists of a server application, two parking spaces with IoT parking sensors, and a video surveillance camera to recognize vehicle license plates. The server application with a database is in charge of storing data on test users of the system and for storing and processing data received from IoT parking sensors and video surveillance cameras. The server application was implemented in the MS Visual Studio 2019 programming environment using the C\# programming language. Two types of parking sensors are installed in each parking space. Figure 2. shows the positions of IoT parking sensors in one parking space. IoT sensor type 1 is Sensit by Nedap [14]. These sensors detect the presence of vehicles based on dual detection technology (infrared and magnetic). The sensors are interconnected to form a local wireless sensor network to send parking spot occupancy data. A dedicated device, a data collector, must be present to collect data from the sensors and further forwards it over the Internet to the server application. IoT parking sensor type 2 is an IoT parking sensor by Fleximodo [15]. This sensor also detects the presence of a vehicle based on magnetic detection technology. These sensors use LoraWAN technology for communication [16]. The sensors are connected via the Lora infrastructure of the public company Telekom Srbija and the installation of additional devices for communication over the Internet is not required. Both types of IoT sensors have a battery power supply, making it easier to install because it is unnecessary to implement the power supply installations when installing the sensors. An additional advantage of the IoT parking sensor type 2 is that it can detect the IoT Permit user tags, which allows additional verification of whether a person with disabilities occupies the parking space with a disability (figure 3.) [17].

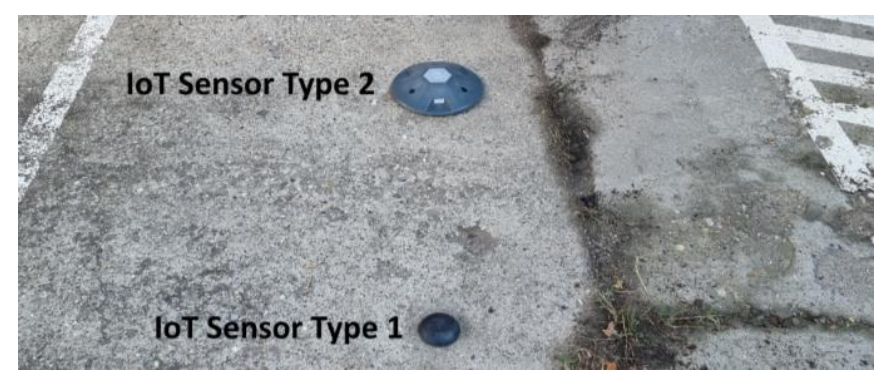

Fig. 2. Position of two types of IoT parking sensors in one parking space

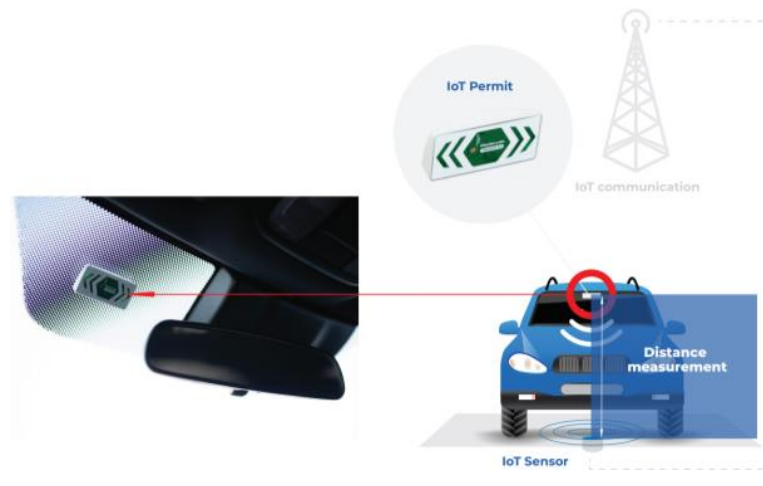

Fig. 3. IoT Permit user tag

An ALPR (Automatic Licence Plate Recognition) camera DS-2CD4A26FWD-IZS/P by Hikvision [18] is used for video surveillance and license plate recognition. This camera can capture vehicles and recognize license plate numbers of various countries and regions. This camera offers high resolution, 2 MegaPixel, 120 dB WDR (Wide Dynamic Range), Auto-iris, PoE (Power over Ethernet), EIS (Electronic Image Stabilization), and 3D DNR (Digital Noise Reduction). Moreover, the camera can recognize a vehicle's plate number in four different lanes automatically. Figure 4 . shows a video surveillance camera that covers both parking spaces. 


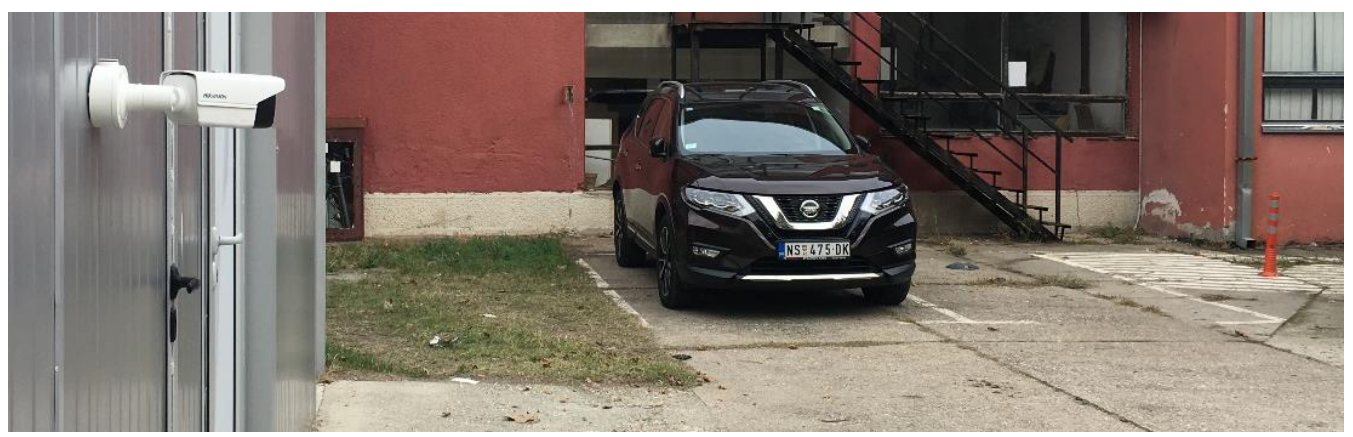

Fig. 4. Position of the camera for video surveillance

For the video surveillance camera and type 1 IoT parking sensors to be able to send data to the server application, the camera and the data collector for type 1 IoT parking sensors are connected to the local network, and the data is sent via the HUAWEI B315S-22 modem configured to work in Telenor mobile network [19]. By setting up such an experiment, we have the opportunity to check all three ways of obtaining data on vehicles in the parking lot, as provided in the SDPS model.

\section{Discussion}

The crucial part of the successful work of SDPS is to obtain timely data on the occupancy of parking spaces reserved for people with disabilities. The worst-case scenario is that there is only reserved parking space for people with disabilities, without IoT parking sensors or video surveillance cameras for vehicle license plates recognition. In that case, the parking enforcement officers must send the data, which can only be expected in paid parking areas. In addition, this information does not have to correspond to the actual situation since the parking enforcement officers stay around one parking space for only ten seconds. There is a bigger problem at the parking areas with free parking because the parking enforcement officers do not control those areas. If the parking spaces are equipped with a camera for recognizing vehicle license plates, then the success of reading license plates in daylight is at best $98 \%$. At the same time, the worst case, which was experimentally determined, is $50 \%$ when night falls and street lighting is not suitable. The best accuracy of parking space occupancy detection is when the parking space is equipped with an IoT parking sensor. In that case, the occupancy detection percentage is over $99 \%$ accurate (only in exceptional circumstances when the battery of the IoT parking sensor is running low and a vehicle with high ground clearance is present, the readings are not reliable). Such a high reading accuracy is present in both types of IoT parking sensors. It took 5 to 10 seconds from changing the state of the parking space to updating the information on the server application when the IoT parking sensor type 1 was used. With a type 2 IoT parking sensor, this time was longer and was 15 to 20 seconds. Although the type 2 IoT parking sensor has a slightly longer response time, its great advantage is that it allows simultaneous checking whether the vehicle belonging to a person with disabilities is parked in a place reserved for them or whether it is illegal parking.

The fact is the number of reserved parking spaces for people with disabilities, especially in paid parking areas, is usually not enough. One way to alleviate this problem is to implement a system (using edge computing and artificial intelligence, including the possibility of different kinds of payments [20]-[24] that allows parking spaces to be shared over time depending on the interest and needs of users. For that purpose, the proposed SDPS model enables the distribution of the time of use of parking spaces reserved for persons with disabilities. The essential condition is that people with disabilities show interest in a specific parking place through the mobile application for SDPS. Then, based on the established priority and the rules determined for using a particular parking space, the SDPS mobile application sends information to users whether the parking space is free or a notification that the period of use of the parking space expires. At the same time, in case of unauthorized use of the parking space, the SDPS system sends a notification to the parking service provider to execute the defined penalty policy (issuance of a fine, removal of the vehicle, etc.).

\section{Conclusion}

People with disabilities often have trouble finding a parking space, especially in paid parking lots. An SDPS model has been proposed to solve this problem. The proposed SDPS model allows time-sharing of parking space usage. The model is made according to the conditions in cities in Serbia, but it can be applied in all cities with minor adjustments. For future work, the realization of a system based on the SDPS model in Novi Sad is planned to perform testing in real conditions. For the proposed SDPS model to function well, two primary conditions must be met. The first condition is that data on the occupancy of parking spaces intended for persons with disabilities are collected in real-time. Another condition is that people with disabilities want to use the applications proposed by the SDPS model. Additional activities in future work will be aimed at exploring new ways of detecting the occupancy of parking spaces reserved for people with disabilities and promoting the proposed solution so that as many people with disabilities as possible use the implemented systems. 


\section{Acknowledgments}

This research has been supported by the Ministry of Education, Science and Technological Development, Government of the Republic of Serbia, through the project: "Innovative scientific and artistic research from the FTN activity domain."

\section{References}

[1] Babic, M.; Vekic, A.; Stanojevic, M.; Ostojic, G.; Borocki, J. \& Stankovski, S. (2019). Modern Parking Solutions for Smart Cities, Proceedings of the 30th DAAAM International Symposium, pp.1075-1083, B. Katalinic (Ed.), Published by DAAAM International, ISBN 978-3-902734-22-8, ISSN 1726-9679, Vienna, Austria DOI: 10.2507/30th.daaam.proceedings. 150

[2] I. Baranovski, S. Stankovski, G. Ostojić, and S. Horvat (2020). "Support for Self-service Automated Parking Systems," in 2020 19th International Symposium INFOTEH-JAHORINA (INFOTEH), pp. 1-5.

[3] D. C. Shoup, (2006). "Cruising for parking," Transp. Policy, vol. 13, no. 6, pp. 479-486

[4] Katanalp, B. Y. , Nennioğlu, A. K. , Özinal, Y., Eren, E. \& Yıldırım, Z. B. (2019). “A design for prevention of violation of disabled parking spaces: DDPS (Deterrent Disabled Parking System)," Eskişehir Osmangazi Üniversitesi Mühendislik ve Mimarlık Fakültesi Dergisi, 27(3), pp. 242-251. DOI: 10.31796/ogummf.594213

[5] Tegeltija, S.; Radovanovic, M.; Babic, M.; Stanojevic, M.; Ostojic, G. \& Stankovski, S. (2020). One Approach to the Detection of Illegal Occupation of Parking Spaces Reserved for Persons with Disabilities, Proceedings of the 31st DAAAM International Symposium, pp.0650- 0655, B. Katalinic (Ed.), Published by DAAAM International, ISBN 978-3-902734-29-7, ISSN 1726-9679, Vienna, Austria DOI: 10.2507/31st.daaam.proceedings.090

[6] S. Tegeltija, M. Babić, L. Tarjan, I. Baranovski and G. Stojanović (2021). "One Solution for Validation of Legal Usage Of Reserved Parking Spaces For People With Disabilities," 2021 20th International Symposium InfotehJahorina (INFOTEH), pp. 1-5, doi: 10.1109/INFOTEH51037.2021.9400689.

[7] https://www.oracle.com/internet-of-things/what-is-iot/. What is IoT? Accessed on: 2021-06-01

[8] Stankovski, S.; Ostojić, G.; Šaponjić, M.; Stanojević, M. \& Babić, M. (2020). "Using micro/mini PLC/PAC in the Edge Computing Architecture," in 2020 19th International Symposium Infoteh-Jahorina (Infoteh), pp. 1-4.

[9] Stankovski, S.; Ostojić, G. \& Zhang, X. (2016). "Influence of Industrial Internet of Things on Mechatronics," Journal of Mechatronics, Automation and Identification Technolgy, vol. 1, no. 1, pp. 1-6.

[10] Stankovski, S.; Ostojić, G.; Baranovski, I.; Babić, M. \& Stanojević, M. (2020). "The Impact of Edge Computing on Industrial Automation," in 2020 19th International Symposium Infoteh-Jahorina (Infoteh), pp. 1-4.

[11] Stankovski, S.; Ostojić, G.; Zhang, X.; Baranovski, I.; Tegeltija, S. \& Horvat, S. (2019). "Mechatronics, Identification Technology, Industry 4.0 and Education," in 2019 18th International Symposium Infoteh-Jahorina (Infoteh) 2019, pp. 1-4.

[12] Sremcev, N., Stevanov, B., Lazarevic, M., Mandic, J., Tesic, Z., Kuzmanovic, B. (2019). "Improving Process of Quotation Creation Through Value Stream Mapping and Simulation, International Journal of Simulation Modelling", Vol. 18, No. 4, pp. 563-573, ISSN 1726-4529

[13] Lazarevic, M., Mandic, J., Sremcev, N., Vukelic, D., Debevec, M. (2019). “A systematic literature review of PokaYoke and novel approach to theoretical aspects", Strojniski vestnik - Journal of Mechanical Engineering, Vol. 65, No. 7-8, pp. 454-467, ISSN 0039-2480

[14] https://portal.nedapidentification.com/download/SENSIT/Datasheet/English/SENSIT\%20IR\%20Flush\%20Mount \%20datasheet/ . SENSIT IR Flush Mount Accessed on: 2021-06-01

[15] https://www.fleximodo.com/. Modular parking solution Accessed on: 2021-06-01

[16] https://lora-alliance.org/about-lorawan/. LoRaWAN Specification Accessed on: 2021-06-01

[17] https://www.fleximodo.com/wp-content/uploads/2021/02/ipermit_datasheet.pdf. IoT Permit card Accessed on: 2021-06-1

[18] https://www.hikvision.com/my/products/IP-Products/Network-Cameras/Ultra-Series-SmartIP-/ds-2cd4a26fwd-lzsp/. Hikvision DS-2CD4A26FWD-IZS/P Accessed on: 2021-06-01

[19] https://www.telenor.rs/webshop/en/Business/Modems/Huawei/B315s-22?purchase=subsidy\&tariff=410. HUAWEI B315S-22 Accessed on: 2021-06-01

[20] S. Nemet, G. Ostojić, D. Kukolj, S. Stankovski, and D. Jovanovic (2019). "Feature Selection Using Combined Particle Swarm Optimization and Artificial Neural Network Approach," Journal of Mechatronics, Automation and Identification Technolgy, vol. 4, no. 1, pp. 7-11

[21] S. Stankovski, G. Ostojić, M. Šaponjić, M. Stanojević, and M. Babić (2020). "Using micro/mini PLC/PAC in the Edge Computing Architecture," in 2020 19th International Symposium Infoteh-Jahorina (INFOTEH), pp. 1-4.

[22] S. Stankovski, G. Ostojić, L. Tarjan, M. Stanojević, and M. Babić (2019). "Challenges of IoT payments in smart services," Ann. DAAAM Proc., vol. 30, 2019.

[23] Baranovski, S. Stankovski, G. Ostojić, S. Horvat, and T. Srdjan (2020). “Augmented reality support for self-service automated systems," J. Graph. Eng. Des., vol. 11, no. 1, p. 63

[24] B. Tejić, S. Tegeltija, S. Horvat, M. Nićin, M. Stanojevič, and M. Babić (2019). "Payment Methods in Vending Machines," Journal of Mechatronics, Automation and Identification Technolgy, vol. 4, no. 3, pp. 20-25 